\title{
DIAGNÓSTICO QUALI-QUANTITATIVO DA ARBORIZAÇÃO VIÁRIA DE NOVA ESPERANÇA, PARANÁ, BRASIL
}

\author{
Ricardo Massulo Albertin ${ }^{1}$; Rafaela De Angelis²; Generoso De Angelis Neto ${ }^{3}$; Bruno Luiz \\ Domingos De Angelis ${ }^{4}$
}

(recebido em 25.08.2010 e aceito para publicação em 15.09.2011)

\section{RESUMO}

A arborização urbana é fundamental para garantir níveis satisfatórios de qualidade de vida, promovendo benefícios para a população. Diante disso, o presente trabalho teve por objetivo fazer um diagnóstico quali-quantitativo da arborização viária da cidade de Nova Esperança, Estado do Paraná, Brasil. Na análise quantitativa, foi realizado censo em 100\% da zona urbana, nas quais as árvores foram identificadas por meio da metodologia usual taxonômica e por consulta bibliográfica específica. Para o diagnóstico qualitativo, foram elaboradas duas planilhas para obtenção dos dados de cada indivíduo arbóreo e arbustivo, tornando-se possível avaliar o estado de conservação das espécies identificadas e caracterizar as que necessitavam de manutenção, trazendo informações sobre o tronco, o sistema radicular, o local de plantio, e o tipo de manejo que deverão receber. Para o preenchimento da planilha, utilizou-se o método do código. Os resultados indicaram que existem 74 espécies e 8.908 indivíduos arbóreos e arbustivos. A maior frequência foi de sibipirunas com $63,44 \%$ e oiti com $14,96 \%$. O trabalho ainda concluiu que $76,9 \%$ das árvores não demandam manutenção e 4,0\% deverão ser erradicadas. Tais informações podem ser úteis ao planejamento da arborização viária do município, contribuindo como subsídio para o direcionamento na tomada de ações a serem realizadas.

Palavras-Chave: Arborização viária; Planejamento urbano; Nova Esperança/PR.

\footnotetext{
1 Geógrafo e Mestre em Engenharia Urbana pela Universidade Estadual de Maringá (UEM), Departamento de Engenharia Civil, Maringá, Paraná, ralbertin@ymail.com;

2 Turismóloga e Mestre em Engenharia Urbana pela Universidade Estadual de Maringá (UEM), Departamento de Engenharia Civil, Maringá, Paraná, rafaangelis@hotmail.com;

3 Prof. Dr., Universidade Estadual de Maringá (UEM), Departamento de Engenharia Civil, Maringá, Paraná, ganeto@.uem.br;

${ }^{4}$ Prof. Dr, Universidade Estadual de Maringá (UEM), Departamento de Agronomia, Maringá, Paraná, brucagem@uol.com.br.
} 


\section{QUALITATIVE AND QUANTITATIVE DIAGNOSIS OF THE URBAN ARBORIZATION IN NOVA ESPERANÇA, PARANÁ, BRAZIL.}

\section{ABSTRACT}

Urban afforestation is essential to secure satisfactory levels of life quality, promoting benefits for the population. Therefore, the present study has had the objective of developing a qualiquantitative diagnosis of the road afforestation in the city of Nova Esperança, State of Paraná, Brazil. In the quantitative analysis, a census was developed in $100 \%$ of the urban zone, where the trees were identified by means of regular taxonomic methodology and by means of specific bibliographic research. For the qualitative diagnosis, two worksheets were elaborated to obtain data from each arboreal and arbustive individual, making it possible to evaluate the conservation state of the identified species and characterize the ones which needed maintenance, bringing information about their trunks, radicular system, planting site, and the type of handling they must receive. In order to fill the worksheets, the method of code was utilized. Results indicated that are 74 species and 8.908 arboreal and arbustive individuals. Those with larger frequency were: the sibipiruna (Caesalpinia peltophoroides), with $63,44 \%$ and the oitis (Licania tomentosa) with $14,96 \%$. The study also concluded that $76,9 \%$ of trees do not require maintenance and $4,0 \%$ must be eradicated. Such information can be useful to the towns road afforestation planning, wich contributes as subsidy to the directions of decision taking to be one.

Keywords: Road Afforestation; Urban Planning; Nova Esperança/PR.

\section{INTRODUÇÃO}

A História da humanidade é pautada, desde seu início, por uma relação íntima homem-natureza. A transposição do tempo via avanço tecnológico afastou o homem de sua vocação original, colocando-o em contato com uma realidade que, mais tarde, mostrou-se questionável do ponto de vista da qualidade ambiental. Nesse contexto se resgata a 
importância do verde para sua vida, uma vez que é crescente o número de pessoas que se mudam do campo para a cidade. Essa vegetação predominantemente arbórea presente em terras públicas e privadas de uma cidade é denominada arborização urbana. Além de considerar áreas de uso público e privado, para Rodrigues et al. (2002, p. 9) somam-se à arborização urbana as árvores de acompanhamento viário:

[...] toda cobertura vegetal de porte arbóreo existente nas cidades. Essa vegetação ocupa, basicamente, três espaços distintos: as áreas livres de uso público e potencialmente coletivas, as áreas livres particulares e acompanhando o sistema viário.

Em sua concepção de arborização urbana, Milano (1990) a considera não apenas espécies arbóreas, mas sim a admite como outras áreas que, independente do porte da vegetação urbana, apresentam-se predominantemente, naturais e não ocupadas.

Seguindo essa mesma ideia, Brandão e Brandão (1992) denominam área verde urbana todo o revestimento vegetal natural ou artificial existente em uma cidade, cujas principais funções se baseiam em promover o bem-estar e o lazer.

Visto que o processo de urbanização é crescente e irreversível, é preciso tornar esse ambiente o mais próximo possível do ambiente natural, conciliando o desenvolvimento com a conservação ambiental e assim, proporcionando uma melhoria na qualidade de vida das populações das cidades.

A arborização deve ser objeto de planejamento prévio de modo que a torne compatível com a área urbana. O plantio de árvores nas cidades já não pode ser realizado de forma amadorística, e as necessidades urbanas a serem mitigadas passam, além do estético, pelos fatores, psicológico, econômico, social, político e da própria sustentabilidade florestal. (GONÇALVES, 1999; GONÇALVES e PAIVA, 2006).

Adotando um conceito moderno sobre as funções da arborização urbana, Fátima (2005, p.12) atribui à esta as seguintes funções:

- Função química: através da absorção de gás carbônico e a liberação de oxigênio;

- Função física: estabilidade climática, diminuição de temperatura e aumento da umidade do ar;

- Melhoria das condições de solo urbano, do ciclo hidrológico redutor de poluição atmosférica e acústica;

- Função paisagística: pela mudança de textura do elemento construído e aspectos estéticos;

- Função psicológica: pelo conforto e bem estar que ela reproduz; 
- Função ecológica: abrigo e alimentação da fauna remanescente, além de contribuir para o aumento da diversidade e da quantidade.

No entanto, hoje, a arborização da maioria das cidades brasileiras não acompanhou a urbanização das mesmas. O processo urbanístico acelerado e desordenado acompanhado pelas inovações tecnológicas vem interferindo na arborização das cidades brasileiras, uma vez que as alterações refletiram na infraestrutura urbana.

Com o surgimento da luz elétrica, a expansão dos serviços de abastecimento de água, de coleta de esgoto e de telecomunicações, um complexo sistema de cabos, galerias e dutos tomaram conta do ar e do subsolo. Como decorrência dessas inovações, pode-se apontar o fato de que a rede aérea passou a interferir no plano de arborização da cidade, com as áreas verdes ficando cada vez mais restritas à arborização de ruas, praças, parques e maciços florestais. É possível observar também que houve perda nos espaços de jardins privados e aumento da impermeabilização do solo (MILANO e DALCIN, 2000 apud BARTOLETO, 2004, p.6)

Encarregar-se do plantio, da preservação e da manutenção da arborização urbana no Brasil faz parte das responsabilidades das administrações municipais. Embora exista uma certa disposição dos órgãos governamentais, das empresas privadas e de grande parcela da população, a arborização urbana tem enfrentado muitos problemas, principalmente nas cidades de médio e grande porte. Entre os problemas estão: a falta de técnicos capacitados que orientem sobre um plantio correto, escolha da espécie, poda de formação, utilização de tutores, grade de proteção, irrigação em período de estiagem e adubação. (RIBEIRO, 2009).

Diante do exposto, a arborização urbana deve ser compreendida como um elemento estruturador do espaço urbano. A inserção, a preservação e a manutenção do verde nas cidades passam a ser grandes desafios para os gestores no novo milênio.

Neste contexto, o presente trabalho teve por objetivo diagnosticar qualiquantitativamente a situação atual da arborização viária da cidade de Nova Esperança, localizada na região Noroeste do estado do Paraná. 


\section{MATERIAIS E MÉTODOS}

\section{Caracterização da área de estudo}

A área de estudo consiste no município de Nova Esperança, que está localizado à Noroeste do Estado do Paraná, região Sul do Brasil, a 600 metros em relação ao nível do mar. Segundo o Instituto Brasileiro de Geografia e Estatísticas (IBGE, 2010), o município tem área de $401,59 \mathrm{~km}^{2}$ e apresenta população total de 26.532 habitantes, com densidade demográfica de 66,9 hab/km².

Geologicamente, o município está inserido no Terceiro Planalto Paranaense, ou Planalto de Guarapuava, mais precisamente no sub planalto de Apucarana, sendo o substrato composto por rochas básicas e arenitos da era mesozoica. O relevo apresenta uma morfologia suavemente ondulada e as cotas hipsométricas variam de 400 a $610 \mathrm{~m}$. Os solos predominantes no município são: Latossolo vermelho; Podzólico vermelho; Solos rasos; solos com hidromorfia; areias quartzosas e solos coluviais (MAACK, 1981).

Nova Esperança está locada no interflúvio de divisor das bacias hidrográficas do Rio Ivaí e Paranapanema. Apresenta verões caracterizados por chuvas abundantes e estação excessivamente úmida, porém no inverno a situação se inverte, ou seja, ocorre ausência de chuvas e, consequentemente, estação mais seca. A pluviosidade média anual é de 1200 a $1500 \mathrm{~mm}$, sendo os meses mais chuvosos de outubro a janeiro (ITCG, 2011).

\section{Levantamento quantitativo das árvores}

Para identificar as árvores, utilizou-se a metodologia usual taxonômica e consulta bibliográfica específica baseada em SOUZA;LORENZI (2008). O sistema de classificação foi baseado em APG II (2003). Formaram-se seis equipes, cada qual composta de um estudante e um especialista em identificação de espécies. As visitas a campo foram realizadas no mês de agosto de 2009. Na ocasião, realizou-se levantamento censo, no qual foram percorridos todos os logradouros do município, diagnosticando $100 \%$ dos indivíduos arbustivos e arbóreos de acompanhamento viário. 


\section{Levantamento qualitativo das árvores}

Para obtenção dos dados de cada indivíduo arbóreo, foram elaboradas duas planilhas: a primeira contendo informações referentes ao quantitativo de espécies identificadas. Essa planilha diz respeito às árvores que apresentam satisfatório estado de conservação, não necessitando de manejo; a segunda planilha, denominada de "Planilha de Manejo", tem por objetivo caracterizar cada indivíduo que necessita de manutenção, trazendo informações sobre o tronco, o sistema radicular, local de plantio, assim como o tipo de manejo que o cada indivíduo deverá receber, ou seja, o tipo e a fase de manutenção. Para a elaboração dessa planilha, utilizou-se o método do código, em que cada item corresponde a um código diferente (Tabela 1). Além disso, foi utilizada uma planilha para obtenção dos dados de localização e caracterização do meio. Esta, por sua vez, traz informações referentes ao número da quadra (identificação numérica da quadra onde se localiza a rua); número da casa; existência de fiação aérea; e falha (local ou espaço que não existe árvore).

Tabela 1. Planilha utilizada para caracterização da árvore utilizando código representativo

Table 1. Worksheet utilized for characterization of the tree using representative code

\begin{tabular}{|c|c|c|c|}
\hline \multicolumn{4}{|c|}{ Caracterização da Árvore } \\
\hline \multicolumn{4}{|c|}{ Identificação da árvore: nome da espécie } \\
\hline \multicolumn{4}{|c|}{ Altura em metros: altura da árvore } \\
\hline \multicolumn{4}{|c|}{ Diâmetro da copa: tamanho da projeção da copa } \\
\hline \multicolumn{4}{|c|}{ Diâmetro da altura do peito (DAP): é o diâmetro do tronco da árvore a altura do peito } \\
\hline \multicolumn{4}{|c|}{ Idade: estimativa da idade da árvore em anos } \\
\hline Tronco & $\begin{array}{c}\text { Sistema } \\
\text { radicular }\end{array}$ & $\begin{array}{c}\text { Local de } \\
\text { plantio }\end{array}$ & Tipo/fase de manutenção \\
\hline 0 - sem defeito & 0 - subterrânea & $\begin{array}{l}0 \text { - entre meio } \\
\text { metro a um } \\
\text { metro do meio } \\
\text { fio }\end{array}$ & 0 - não demanda manutenção \\
\hline $\begin{array}{l}1 \text { - danificado } \\
\text { por poda leve } \\
\text { ou quebra de } \\
\text { galho }\end{array}$ & 1 - superficial & $\begin{array}{l}1 \text { - próximo ao } \\
\text { muro ou ao } \\
\text { meio fio }\end{array}$ & $\begin{array}{l}1 \text { - satisfatória, demanda apenas podas } \\
\text { de formação }\end{array}$ \\
\hline $\begin{array}{l}2 \text { - poda de } \\
\text { formação mal } \\
\text { conduzida }\end{array}$ & $\begin{array}{l}2 \text { - superficial } \\
\text { com rachadura } \\
\text { na calçada }\end{array}$ & $\begin{array}{l}2 \text { - atrapalhando } \\
\text { o trânsito de } \\
\text { pedestre }\end{array}$ & $\begin{array}{l}2 \text { - condição geral boa: árvore } \\
\text { aparentemente boa, vigorosa, que não } \\
\text { apresenta sinais de pragas, doenças ou } \\
\text { injúrias mecânicas, que apresenta a forma } \\
\text { características da espécie e não requer } \\
\text { trabalhos de correção e grande amplitude: } \\
\text { necessita apenas podas de manutenção }\end{array}$ \\
\hline
\end{tabular}




\begin{tabular}{|c|c|c|c|}
\hline $\begin{array}{l}3 \text { - atacado por } \\
\text { cupim e/ou } \\
\text { fungos com } \\
\text { possibilidade de } \\
\text { recuperação }\end{array}$ & $\begin{array}{l}5 \text { - comprometida } \\
\text { com tombamento } \\
\text { de árvore }\end{array}$ & $\begin{array}{l}4 \text { - atrapalhando } \\
\text { placas de } \\
\text { trânsito, } \\
\text { garagem, } \\
\text { sinalização } \\
\text { (infraestrutura } \\
\text { em geral) }\end{array}$ & $\begin{array}{l}3 \text { - condição geral regular: pode } \\
\text { apresentar pequenos problemas de } \\
\text { pragas, doenças ou injúrias mecânicas, } \\
\text { pode necessitar poda corretiva, limpeza, } \\
\text { reparos de danos físicos ou controle de } \\
\text { pragas e doenças }\end{array}$ \\
\hline $\begin{array}{l}4 \text { - ocado, com } \\
\text { cupim e/ou } \\
\text { fungos e de } \\
\text { difícil } \\
\text { possibilidade de } \\
\text { recuperação }\end{array}$ & & $\begin{array}{l}5 \text { - esquina } \\
\text { atrapalhando o } \\
\text { tráfego de } \\
\text { veículos }\end{array}$ & $\begin{array}{l}4 \text { - condição geral sofrível: árvore que } \\
\text { apresenta estado geral de declínio e pode } \\
\text { apresentar severos danos de pragas, } \\
\text { doenças ou danos físicos sérios em } \\
\text { estágio avançado. Embora muitas vezes } \\
\text { não aparente morte eminente, pode } \\
\text { requerer muito trabalho de recuperação. } \\
\text { Dependendo do indívíduo, este item pode } \\
\text { ser considerado uma erradicação a médio } \\
\text { ou longo prazo. Espécies não } \\
\text { recomendadas, quando for o caso, podem } \\
\text { ser erradicadas a médio ou longo prazo. }\end{array}$ \\
\hline $\begin{array}{l}5 \text { - copa } \\
\text { definhando ou } \\
\text { morta }\end{array}$ & & & $\begin{array}{l}5 \text { - condição de erradicação urgente: } \\
\text { árvore que apresenta estado geral com } \\
\text { risco de tombamento e/ou sérios danos } \\
\text { de pragas, doenças ou danos físicos com } \\
\text { estágio avançado, sem possibilidade de } \\
\text { recuperação (morta e/ou definhando) }\end{array}$ \\
\hline
\end{tabular}

\section{RESULTADOS E DISCUSSÃO}

\section{Levantamento quantitativo}

Os resultados do processo de amostragem por meio de visitas técnicas realizadas em toda a cidade de Nova Esperança identificaram 8.908 espécies vegetais de porte arbóreo (Tabela 2).

Tabela 2. Ocorrência das espécies arbóreas na cidade de Nova Esperança. Número absoluto (№) e Percentual (\%)

Table 2. Occurrence of the arboreal species in the City of Nova Esperança. Absolute number (№) and percentage (\%).

\begin{tabular}{l|l|c|c|c|c}
\hline \multicolumn{1}{c|}{ Nome Vulgar } & \multicolumn{1}{|c|}{ Nome Científico } & № & (\%) & Origem & Família \\
\hline Sibipiruna & $\begin{array}{l}\text { Caesalpinia peltophoroides } \\
\text { Benth. }\end{array}$ & 5651 & 63,44 & Nativa & Fabaceae \\
\hline Oiti & $\begin{array}{l}\text { Licania tomentosa (Benth.) } \\
\text { Fritsch }\end{array}$ & 1333 & 14,96 & Nativa & Chrysobalanaceae \\
\hline Ipê & $\begin{array}{l}\text { Pouteria grandiflora (Wall) } \\
\text { Baehni }\end{array}$ & 377 & 4,23 & Nativa & Bignoniaceae \\
\hline Aroeira salsa & Schinus molle L. & 276 & 3,01 & Nativa & Anacardiaceae \\
\hline Monguba & Pachira aquatica Aubl. & 236 & 2,65 & Nativa & Bombacaceae \\
\hline
\end{tabular}




\begin{tabular}{|c|c|c|c|c|c|}
\hline Ligustrum & Ligustrum lucidum Aiton & 195 & 2,19 & Exótica & Oleaceae \\
\hline Palmeira Real & $\begin{array}{l}\text { Archontophoenix cunninghamii } \\
\text { Wendl. \& Drude }\end{array}$ & 112 & 1,26 & Exótica & Arecaceae \\
\hline Sete copas & Terminalia catappa L. & 104 & 1,17 & Exótica & Combretaceae \\
\hline Ficus & Ficus benjamina L. & 83 & 0,93 & Exótica & Moraceae \\
\hline Palmeira imperial & Roystonea regia Kunth & 80 & 0,9 & Exótica & Arecaceae \\
\hline Quaresmeira & $\begin{array}{l}\text { Tibouchina granulosa (Desr.) } \\
\text { Cogn. }\end{array}$ & 72 & 0,81 & Nativa & Melastomataceae \\
\hline Flamboyant & Delonix regia Raf. & 65 & 0,73 & Exótica & Fabaceae \\
\hline Pata de vaca & $\begin{array}{l}\text { Bauhinia variegata var. } \\
\text { candida (Roxb.) Voigt }\end{array}$ & 42 & 0,47 & Exótica & Fabaceae \\
\hline Não identificado & --------- 1 - & 31 & 0,35 & --------- & --------- \\
\hline Magnólia & Magnolia grandiflora L. & 29 & 0,33 & Exótica & Magnoliaceae \\
\hline Mangueira & Mangifera indica $\mathrm{L}$. & 16 & 0,18 & Exótica & Anacardiaceae \\
\hline Grevílea & Grevillea robusta Cunn & 14 & 0,16 & Exótica & Proteaceae \\
\hline Goiabeira & Psidium guajava L. & 13 & 0,15 & Nativa & Myrtaceae \\
\hline Murta & Murraya paniculata (L.) Jack & 12 & 0,13 & Exótica & Myrtaceae \\
\hline Cedrinho & Cupressus Iusitânica Mill. & 10 & 0,11 & Exótica & Cupressaceae \\
\hline Pingo de ouro & Duranta repens L. & 9 & 0,1 & Exótica & Verbenaceae \\
\hline Ameixa & $\begin{array}{l}\text { Eriobotrya japonica (Thumb.) } \\
\text { Lindl. }\end{array}$ & 7 & 0,08 & Exótica & Rosaceae \\
\hline Alecrim & Holocalyx balansae Micheli & 6 & 0,07 & Nativa & Fabaceae \\
\hline Castanha do Pará & $\begin{array}{l}\text { Bertholletia excelsa Humb. \& } \\
\text { Bonpl }\end{array}$ & 6 & 0,07 & Nativa & Lecythidaceae \\
\hline Jambolão & Syzygium cumini L. & 6 & 0,07 & Exótica & Myrtaceae \\
\hline Leucena & Leucaena leucocephala Lam. & 6 & 0,07 & Exótica & Fabaceae \\
\hline Pinus & Pinus echinata L. & 6 & 0,07 & Exótica & Pinaceae \\
\hline Romãzeira & Punica granatum L. & 6 & 0,07 & Exótica & Lythraceae \\
\hline Abacateiro & Persea americana Mill & 5 & 0,06 & Exótica & Lauraceae \\
\hline Acácia Imperial & Cassia ferruginea Schrad & 6 & 0,07 & Exótica & Fabaceae \\
\hline Jaca & Artrocarpus heterophyllus Lam. & 5 & 0,06 & Exótica & Moraceae \\
\hline Laranjeira & Citrus sinensis $\mathrm{L}$. & 5 & 0,06 & Exótica & Rutaceae \\
\hline Pinha & Rollinia mucosa Baill & 5 & 0,06 & Exótica & Annonaceae \\
\hline Santa Bárbara & Melia azedarach L. & 5 & 0,06 & Exótica & Meliaceae \\
\hline Acerola & Malpighia glabra L. & 4 & 0,04 & Exótica & Malpighiaceae \\
\hline Canelão & $\begin{array}{l}\text { Nectandra membranácea } \\
\text { Swartz }\end{array}$ & 4 & 0,04 & Nativa & Lauraceae \\
\hline Guaritá & Astronium graveolens Jacq. & 4 & 0,04 & Nativa & Anacardiaceae \\
\hline Jatobá & Hymenaea courbaril $\mathrm{L}$. & 4 & 0,04 & Nativa & Fabaceae \\
\hline Cedro & Cupressus lusitânica Mill & 3 & 0,03 & Exótica & Meliaceae \\
\hline Falso Pau Brasil & Caesalpinia sappan L. & 3 & 0,03 & Exótica & Rhamnaceae \\
\hline Hibisco & Hibiscus rosa-sinensis L. & 3 & 0,03 & Exótica & Malvaceae \\
\hline Ingá & Inga cylindrica Vell & 3 & 0,03 & Nativa & Fabaceae \\
\hline Limoeiro & Citrus limonium (L.) Burm. f. & 3 & 0,03 & Exótica & Rutaceae \\
\hline Pau Brasil & Caesalpinia echinata Lam & 3 & 0,03 & Nativa & Fabaceae \\
\hline Pitangueira & Eugenia uniflora L. & 3 & 0,03 & Nativa & Myrtaceae \\
\hline Algodoeiro/Paineira & Eriotheca pentaphylla Vell. & 2 & 0,02 & Nativa & Bombacaceae \\
\hline Arueira Pimenta & Schinus terebinthifolius Raddi & 2 & 0,02 & Nativa & Anacardiaceae \\
\hline Coqueiro & Cocos nucifera L. & 2 & 0,02 & Nativa & Arecaceae \\
\hline Espirradeira & Nerium oleander $\mathrm{L}$. & 2 & 0,02 & Exótica & Apocynaceae \\
\hline Gurucaia & Parapiptadenia rígida Benth. & 2 & 0,02 & Nativa & Fabaceae \\
\hline Palmeira rabo de peixe & Caryota mitis Lour. & 2 & 0,02 & Exótica & Arecaceae \\
\hline Pau ferro & $\begin{array}{l}\text { Caesalpinia paraguariensis } \\
\text { Burk }\end{array}$ & 2 & 0,02 & Nativa & Fabaceae \\
\hline Reseda & Lagerstroemia indica L. & 2 & 0,02 & Exótica & Lythraceae \\
\hline Acácia Javanesa & Cassia javanica Riad & 2 & 0,02 & Exótica & Fabaceae \\
\hline Amora & Morus alba L. & 1 & 0,01 & Exótica & Moraceae \\
\hline Araucária & Araucaria angustifolia Bert. & 1 & 0,01 & Nativa & Araucariaceae \\
\hline Bananeira & Musa paradisíaca $\mathrm{L}$. & 1 & 0,01 & Exótica & Musaceae \\
\hline Brinco de Princesa & Schotia brachipetala Sond & 1 & 0,01 & Exótica & Onagraceae \\
\hline
\end{tabular}




\begin{tabular}{l|l|c|c|c|c}
\hline Calistemon & Callistemon speciosus DC & 1 & 0,01 & Exótica & Myrtaceae \\
\hline Canafístula & Albizia inundata Mart. & 1 & 0,01 & Nativa & Fabaceae \\
\hline Dama da Noite & Cestrum nocturnum L. & 1 & 0,01 & Exótica & Solanaceae \\
\hline Figueira & Coussapoa microcarpa Schott & 1 & 0,01 & Exótica & Moraceae \\
\hline Imbu & Spondias tuberosa A. Camara & 1 & 0,01 & Nativa & Anacardiaceae \\
\hline Jabuticabeira & Myrciaria cauliflora Berg & 1 & 0,01 & Nativa & Myrtaceae \\
\hline Jambo & Syzygium aqueum L. & 1 & 0,01 & Exótica & Myrtaceae \\
\hline Leiteiro & Peschiera fuchsiaefolia Miers & 1 & 0,01 & Nativa & Apocynaceae \\
\hline Macaúba & Acrocomia aculeata Jacq. & 1 & 0,01 & Nativa & Arecaceae \\
\hline Palmeira cica & Cycos circinalis L. & 1 & 0,01 & Exótica & Cycadaceae \\
\hline Pinheiro & Pinus echinata Mill. & 1 & 0,01 & Exótica & Pinaceae \\
\hline Tipuana & Tipuana tipu Benth & 1 & 0,01 & Nativa & Fabaceae \\
\hline TOTAL & --------- & $\mathbf{8 9 0 8}$ & $\mathbf{1 0 0}$ & --------- & -------- \\
\hline
\end{tabular}

Nova Esperança possui 74 espécies na arborização viária. Comparando com outras cidades do mesmo porte apresentadas em estudos científicos, pode-se concluir que a cidade é bem provida em variabilidade de espécies. Para Lima (1995), a diversificação das espécies é fundamental para contribuir com melhoria da estética do ambiente e redução de ataques de pragas. Neste aspecto, Santamour (1990) determina que não se deva ter mais de $10 \%$ de uma única espécie de árvore; não mais de $20 \%$ de um único gênero de árvore; não mais de $30 \%$ de espécies da mesma família.

A espécie sibipiruna (Caesalpinia peltophoroides) está fora do padrão proposto por Grey e Deneke (1978), que permite uma frequência de 10 até $15 \%$ em zonas urbanas de uma mesma espécie. Deste modo, os riscos ficam mais distribuídos, evitando que a arborização de ruas de uma cidade seja dizimada por um surto de pragas e doenças. Podemos observar que a sibipiruna corresponde a $63,44 \%$ do total. Desta forma, a composição da arborização de vias públicas de Nova Esperança está focada, principalmente, nesta espécie.

Um problema muito comum encontrado na cidade foi a quantidade de espécies não recomendadas para a arborização viária. Foram encontradas muitas espécies de frutíferas, como a jaqueira e a mangueira. O fícus (Ficus benjamina), outra espécie muito comum nos logradouros de Nova Esperança, apresenta um grande valor ornamental pelas folhas e pela forma geral da planta, podendo ser utilizados tanto em jardins como em interiores. Não é recomendado para a arborização viária, pois o sistema radicular danifica drasticamente vias de passeio, ruas e avenidas. Foram encontrados exatamente 83 indivíduos dessa espécie na cidade.

Identificaram-se, também, espécies proibidas legalmente, como a Murta (Murraya

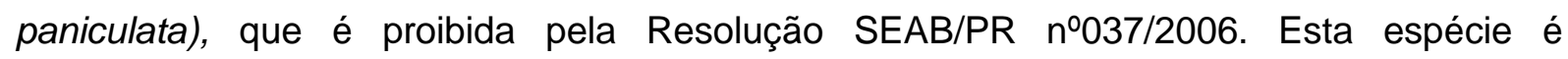
hospedeira de uma bactéria (Candidatus liberibacter spp.), agente causador Huanglongbing- 
HLB (greening) e do inseto vetor Diaphorina citri, sendo uma ameaça potencial para a citricultura do estado do Paraná (PARANÁ, 2006).

\section{Levantamento qualitativo}

Com o intuito de conhecer a qualidade geral dos indivíduos arbóreos, realizou-se uma avaliação individual das árvores.

Em geral foi verificada uma alta porcentagem de árvores em condições que não demandam manutenção, porém isso não significa que a árvore contenha algum outro tipo de problema, como por exemplo, sistema radicular danificando meio fio, ou poda mal executada. Verificou-se também que $4 \%$ das árvores presentes no município estão em condição de erradicação urgente. São árvores que estão definhando, com tronco ocado ou plantado em local inadequado.

Observou-se em Nova Esperança que das 6.796 árvores, 8.908 não necessitam nenhum tipo de manutenção, ou seja, $76,9 \%$ de todos os indivíduos estão em perfeito estado e $23,1 \%$ apresentam outras características.

\section{Tronco}

O tronco é fundamental para a sustentação de toda a estrutura da árvore. Das 8.908 árvores analisadas, 1.409 apresentaram defeitos no tronco decorrentes de podas mal conduzidas, presença de cupins, fungos, podridão e copas definhadas ou mortas.

Árvores que foram danificadas por poda leve ou quebra de galho corresponderam a $3 \%$ do total dos problemas verificados, totalizando 43 indivíduos. Não estão incluídas nesse aspecto árvores danificadas por poda mal executada ou poda pesada, ou seja, aquelas que não apresentaram critérios técnicos específicos para sua execução. A poda de formação mal conduzida foi um problema encontrado ex

Exclusivamente nas árvores jovem presentes na cidade. Elas precisam de poda técnica específica para poder desenvolver-se relativamente bem. Esse problema está presente em 329 árvores. Quanto ao aspecto atacado por cupim ou fungo e com possibilidade de recuperação, não foram identificadas as espécies de cupins, mas apenas 
seus vestígios e presença. Esses foram verificados por meio da visualização de caminhos, ninhos arborícolas e galerias (Figura 1).

Figura 1. Árvore comprometida por ataque de cupim

Figure 1. Damaged tree due to termite attack

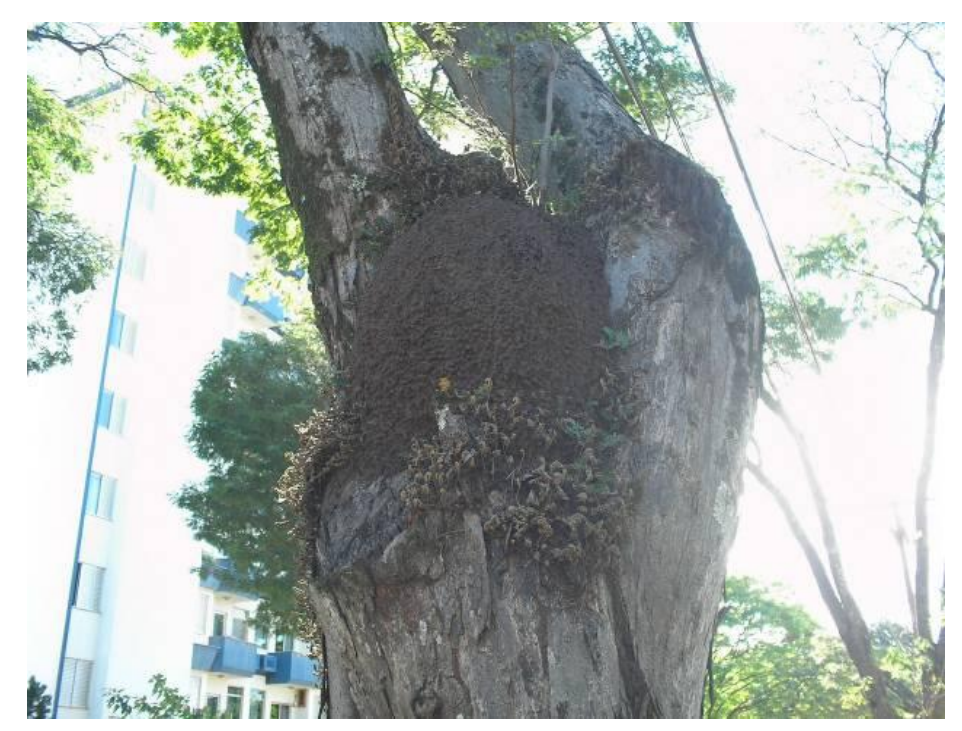

Fonte: Ricardo Massulo Albertin, 09/08/2009.

O estudo realizado considerou a presença ou vestígios de cupins como um bioindicador negativo de qualidade, ou seja, as árvores nas quais se detectaram cupins foram enquadradas em condições de possibilidade de recuperação ou, em casos mais graves, erradicação. Foram diagnosticadas 350 árvores com a presença ou vestígios de cupins, isso corresponde a $25 \%$ do total dos problemas encontrados no tronco das árvores. Em $80 \%$ dos casos, a espécie mais atingida foi a sibipiruna (Caesalpinia peltophoroides). Em zonas mais antigas ou centrais, a frequência de cupins se mostrou mais elevada devido, principalmente, à idade mais avançada das árvores.

Assim como acontece com os cupins, a incidência de fungos funciona como um bioindicador da qualidade da árvore, pois a presença de fungos indica deterioração da madeira do interior. Foi observada a presença de fungos no tronco e na copa. Árvores ocadas (Figura 2), com cupim e/ou com podridão se apresentam de difícil possibilidade de recuperação, podendo, na maioria dos casos, serem erradicadas a médio (2 anos) ou longo prazo (de 3 a 5 anos). 
Figura 2. Tronco com infestação de cupim e cancro

Figure 2. Termite infested trunk and chancre

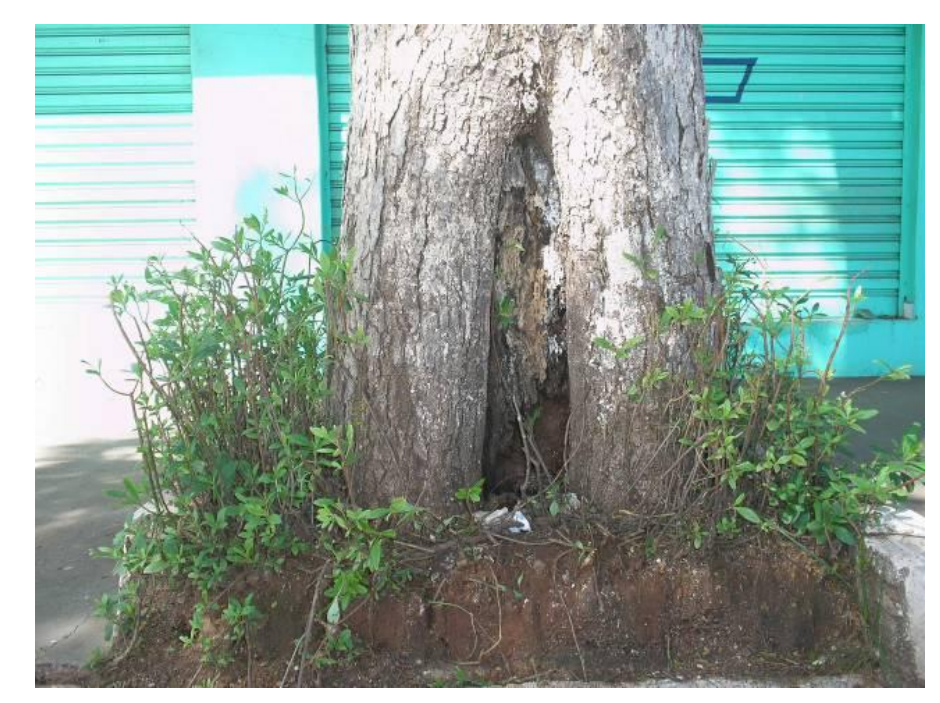

Fonte: Ricardo Massulo Albertin 09/08/2009

Árvores que apresentam copa definhando ou morta são aquelas sem possibilidade de recuperação, ou seja, deverão ser erradicadas. O total correspondente desse tipo de problema foi de 116 árvores.

\section{Sistema radicular}

Os conflitos com os logradouros referem-se aos danos que as raízes causam nos passeios, vias de veículos (ruas e avenidas) e meio-fio. Nesse item são apresentados qualitativamente e quantitativamente os principais problemas encontrados no sistema radicular das árvores presentes no município de Nova Esperança - PR.

As árvores que não apresentaram danos superficiais totalizam 7.501 indivíduos. Árvores que apresentaram o sistema radicular de forma superficial não ocorrendo danificação de calçadas, meio-fio e vias de trânsito correspondem a 314 indivíduos. Já as árvores que apresentaram o sistema radicular superficial com rachaduras nas calçadas, meio-fio ou vias de trânsito correspondem a 1023 indivíduos. As espécies que mais se inserem nestes casos são sibipirunas, sete copas, flamboyant e fícus (Figura 3). As árvores com sistema radicular comprometido com risco de tombamento corresponderam a 70 indivíduos. 
Figura 3. Vista parcial de sistema radicular superficial destruindo vias de passeio Figure 3. Partial view of the superficial radicular system destroying walking ways

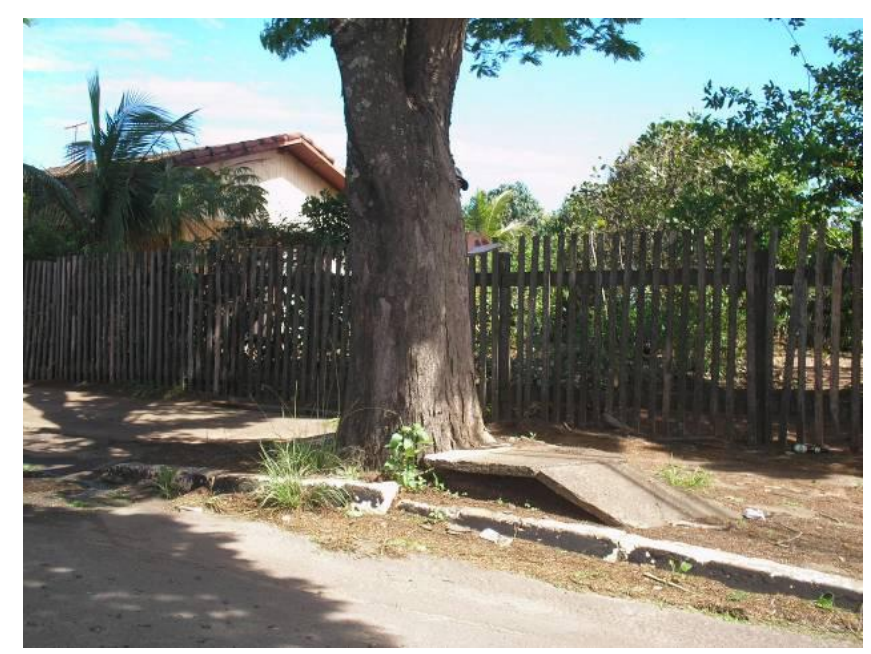

Fonte: Ricardo Massulo Albertin, 09/08/2009

\section{Local de plantio das árvores}

As árvores plantadas em locais adequados, ou seja, entre meio metro a um metro do meio fio representaram 8.595 indivíduos, correspondendo a $96 \%$ do total. Os $4 \%$ restantes encontram-se plantadas em locais considerados inadequados.

Árvores locadas próximo ao muro ou ao meio fio representaram 150 indivíduos. As que estão atrapalhando o trânsito de pedestre, ou seja, estão de alguma forma interferindo na passagem de pessoas somaram um total de 68. Os indivíduos que estão atrapalhando placas de trânsito, sinalização, garagem, rampas, e infraestrutura geral, como bueiros (Figura 4) totalizaram 78 árvores. Já as que estão localizadas próximas às esquinas, atrapalhando o tráfego de veículos, somaram 17 indivíduos. 
Figura 4. Vista parcial de sistema radicular superficial destruindo vias de passeio

Figure 4. Partial view of superficial radicular system destroying walking ways

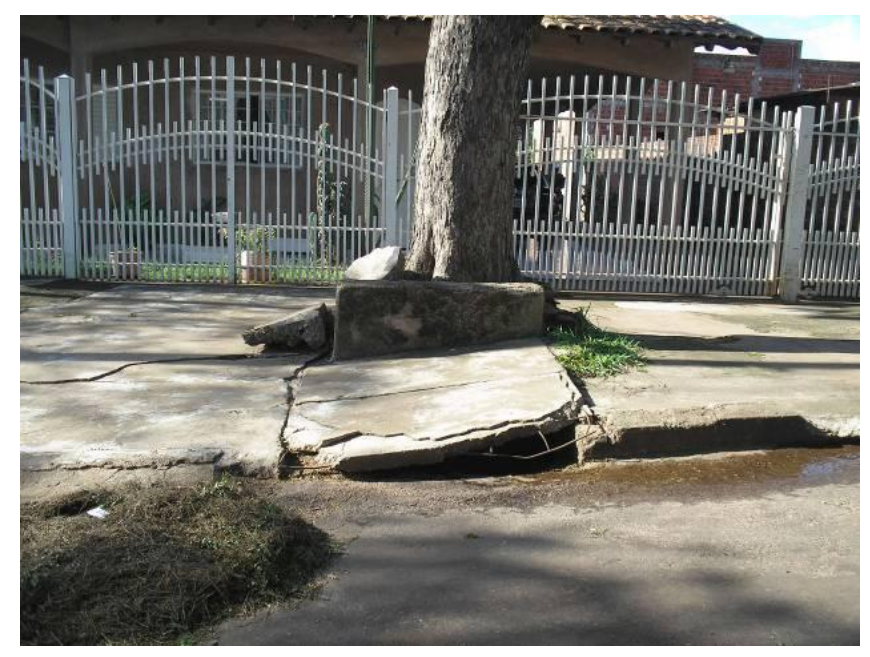

Fonte: Ricardo Massulo Albertin, 09/08/2009

\section{Problemas diversos}

Quanto às podas, os resultados mostraram que este tipo de manejo deverá ser realizado em 1.194 árvores, em sua maioria da espécie sibipiruna (Caesalpinia peltophoroides) alfeneiro/ligustrum (Ligustrum lucidum). O serviço a ser realizado é a poda de limpeza, para retirada de galhos doentes e secos, e a poda de emergência para afastamento de galhos da rede elétrica. Espécies como Oiti e Aroeira Salsa recomenda-se a poda de formação.

Foi avaliada a qualidade da execução das podas e em muitos casos verificou-se copa danificada e galhos pendendo para um dos lados (Figura 5). Segundo Balensieder e Wiecheteck (1987) as podas drásticas são muito antieconômicas, sendo que após sua execução ocorre uma brotação epicórmica nas proximidades do corte e os novos ramos tendem a uma posição ascendente.

O maior responsável pela má execução desse serviço é a empresa responsável pelo abastecimento de energia elétrica na cidade, que realizou as podas fora de um padrão técnico, dificultado, principalmente, pela rede convencional, que exige podas drásticas, pois o contato dos galhos com o condutor nu pode provocar desligamento da rede (Sardeto, 1999 apud Velasco, 2006) Um exemplo para correção deste problema vem da cidade de 
Maringá, estado do Paraná. Neste município, a prefeitura municipal, com apoio da companhia de abastecimento de energia elétrica e empresas privadas, realizou a implantação da rede compactada protegida em 98\% da cidade (RECCO, 2005).

A implantação da rede compactada tem um custo relativamente igual à rede convencional. Isso foi demonstrado por Velasco et al. (2006), onde concluiu que os custo de implantação da rede convencional variou de $\mathrm{R} \$ 54.188,39$ a $\mathrm{R} \$ 67.571,43$. O custo de implantação de rede compacta (primária e secundária) foi, em média, $R \$ 62.215,99$. O autor afirma que "a rede compacta já é totalmente viável, principalmente por ter custo de implantação praticamente igual à rede convencional e ter custo de manutenção $80 \%$ menor".

Figura 5. Poda drástica executada na espécie Sibipiruna

Figure 5. Drastic pruning performed on Sibipiruna species

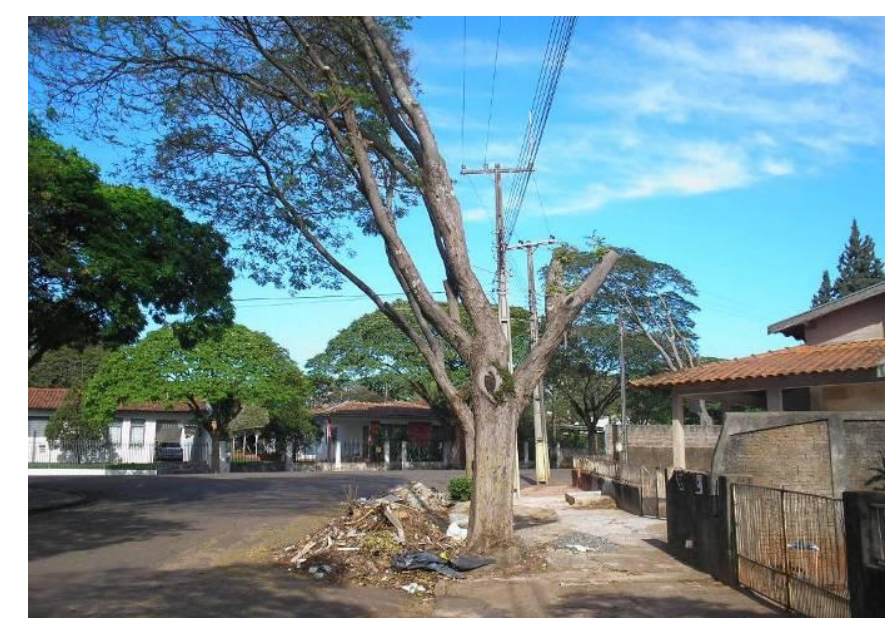

Fonte: Ricardo Massulo Albertin, 09/08/2009

As árvores que apresentaram boa condição geral são vigorosas e não apresentaram sinais de pragas, doenças ou injúrias mecânicas, porém necessitam de podas de manutenção. Esses casos representaram um total de 485 indivíduos.

As árvores com condição geral regular podem apresentar pequenos problemas de pragas, doenças ou injúrias mecânicas, necessitar poda corretiva ou até de limpeza, reparos de danos físicos ou controle de pragas e doenças. Esse caso totalizou 704 indivíduos

A condição geral sofrível são árvores com estado geral de declínio e pode apresentar severos danos de praga, doenças ou danos físicos sérios ou em estágio avançado, e, embora muitas vezes não aparente morte eminente, pode requerer muito trabalho de recuperação. Dependendo do indivíduo, esse item pode ser considerado uma erradicação a 
médio ou longo prazo. Ao total foram diagnosticados 578 indivíduos nessas condições. Convém considerar que espécies não recomendadas para arborização viária foram enquadradas, dependendo o caso, nesse item.

Árvores com condição de erradicação urgente são as que representam risco de tombamento e/ou sérios danos de praga, doenças ou danos físicos sérios com estágio avançado, sem possibilidade de recuperação (morta e/ou definhando), representando um total de 340 indivíduos.

Foram identificados os locais onde necessitam ser plantadas árvores. Ao total poderão ser plantadas em toda a cidade 4.093 indivíduos arbóreos.

$\mathrm{Na}$ arborização viária, o porte das árvores deve estar em sintonia com o espaço disponível. Árvores de menor porte deverão ser plantadas em ruas mais estreitas, as de porte mediano a grande em ruas largas ou em avenidas providas de canteiros centrais. Considerando a presença de outros elementos que compõem a infraestrutura urbana, destaca-se que é de suma importância a escolha correta das espécies arbóreas a serem implantadas no perímetro urbano. Além disso, deve-se efetuar o plantio correto, preparando a cova consoante com o sistema radicular, assim como distância segura às valas de canalização (SAMPAIO, 2006).

O espaço físico disponível (Figura 6) para o plantio da árvore, na maioria dos casos, é relativamente pequeno, assim o sistema radicular destrói as vias de passeio de pedestres (calçadas) e em alguns casos o meio fio e as vias de trânsito.

Figura 6. Espaço físico disponível ausente

Figure 6. Absent available physical space

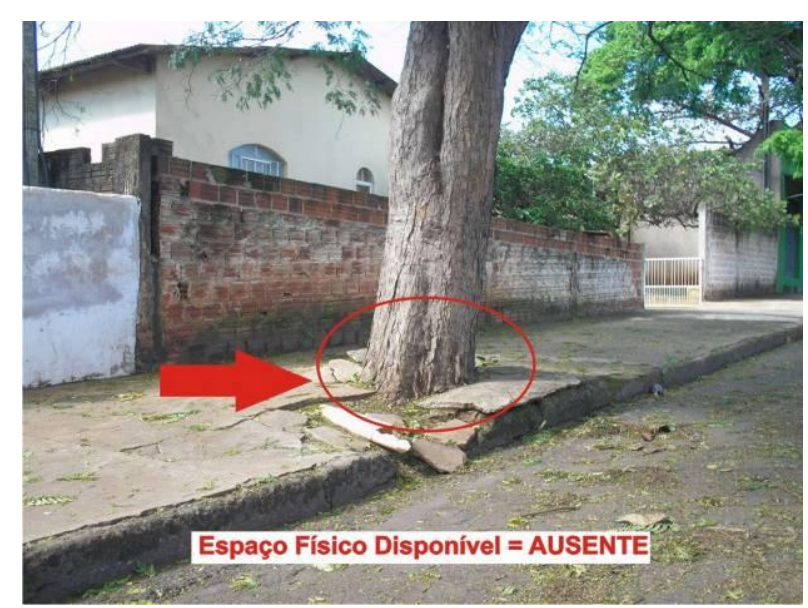

Fonte: Ricardo Massulo Albertin, 09/08/2009 
Nos novos loteamentos, a Prefeitura Municipal de Nova Esperança está plantando espécies, focada, principalmente, em apenas duas espécies: o Oiti (Licania tomentosa) e a Aroeira Salsa (Schinus Molle). Deste modo, este planejamento não leva em consideração a diversificação de espécie, gênero e família preconizados por Santamour (1990).

O oiti é uma árvore muito utilizada nos novos loteamentos. Esta espécie pode atingir altura entre 8 e 15 metros, sendo uma árvore muito utilizada na arborização urbana e viária, devido, principalmente, à copa frondosa. Todavia, ela requer cuidados especiais, principalmente nos aspectos de poda. Devem-se podar os galhos que estão ligados ao tronco até 1,60m / 1,80m. Assim, as árvores irão se desenvolver sem comprometer a passagem de pedestres e veículos. A Figura 7 traz um exemplo de ausência da poda de formação e a Figura 8 traz o modelo de uma poda de formação executada corretamente.

Figura 7. Poda de formação mal conduzida em espécie oiti

Figure 7. Mismanaged formation pruning on the oiti species

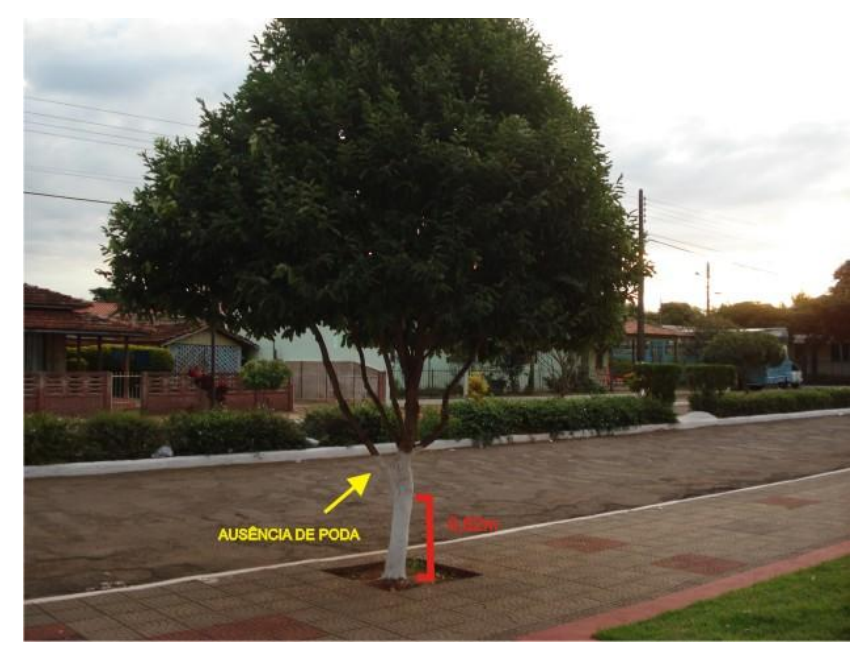

Fonte: Ricardo Massulo Albertin, 09/08/2009 
Figura 8. Poda de formação executada corretamente em espécie oiti

Figure 8 . Correctly managed formation pruning on the oiti species

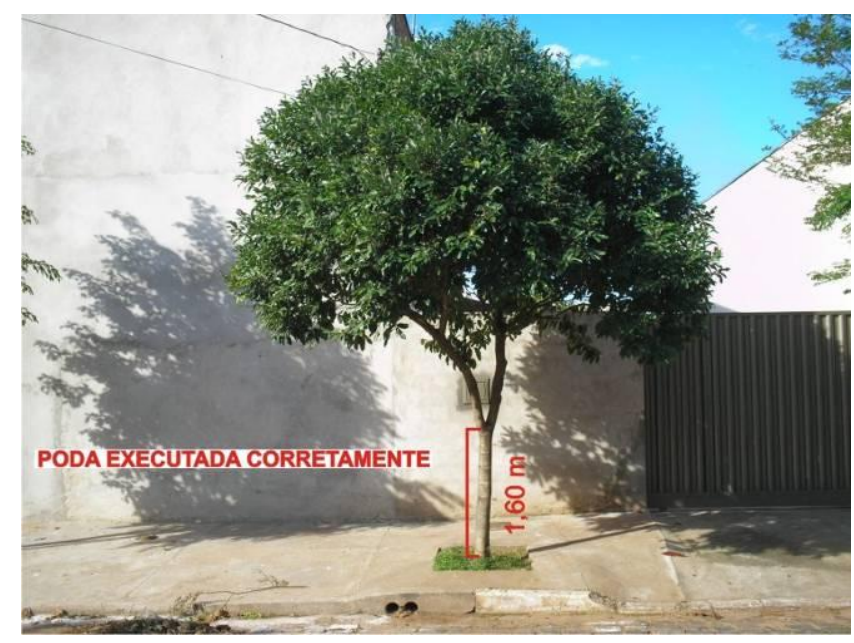

Fonte: Ricardo Massulo Albertin, 09/08/2009

\section{CONCLUSÃO}

Os resultados indicaram que na zona urbana de Nova Esperança existem 74 espécies e 8.908 indivíduos arbóreos e arbustivos. Essa quantidade de espécies indica que, comparada a algumas cidades de mesmo ou maior porte, a cidade é provida de expressiva variabilidade. Por meio de uma avaliação individual das árvores constatou-se, em geral, uma alta porcentagem de exemplares em condições que não demandam manutenção. No entanto, o baixo índice das que necessitam de manutenção ou que precisam ser erradicadas com urgência estão comprometidas por agentes patógenos; podas mal executadas; plantio em locais inadequados; uma significativa ocorrência de Caesalpinia peltophoroides (Sibipiruna), fato que se torna grave caso uma única praga e/ou doença atingir aquela espécie dominante e assim prejudicar toda essa arborização; espécies não recomendadas para a arborização viária como a jaqueira e a mangueira; e a sobreposição de raízes nos passeios públicos.

Portanto, com base nos dados levantados, pode-se afirmar que tanto sob aspectos quantitativos quanto qualitativos a situação da arborização urbana de Nova Esperança é satisfatória. Porém, é oportuno recomendar a adoção de um programa permanente de arborização urbana que vise o monitoramento sistemático dos exemplares, controle das 
podas, combate aos agentes patógenos, substituição e plantio e, desse modo, garantir os inúmeros benefícios da arborização para o ambiente urbano.

\section{AGRADECIMENTOS}

Os autores têm a satisfação de agradecer as equipes de campo, formadas por estagiários do curso de Agronomia da Universidade Estadual de Maringá e por pessoas com ampla experiência em identificação de espécies, em especial o Senhor João do viveiro municipal de Nova Esperança e a equipe técnica da EMATER/PR.

\section{REFERÊNCIAS BIBLIOGRÁFICAS}

APG II. An update of the Angiosperm Phylogeny Group classification for the orders and families of flowering plants: APG II. Botanical Journal of the Linnean Society 141: 399 436, 2003.

BALENSIEFER, M., WIECHETECK, M. Arborização de cidades. . Curitiba: Instituto de Cartografia e Florestas. 1987.

BRANDÃO, M.; BRANDÃO, H. A Árvore: paisagismo e meio ambiente. Belo Horizonte: Viatae Comunicação Integrada, 1992.

FÁTIMA, M. Estudos dos impactos ambientais da interação da rede de distribuição de energia elétrica coma arborização urbana nos municípios da região metropolitana do Recife. Dissertação (Mestrado em Gestão e Políticas Ambientais) - Universidade Federal de Pernambuco, Recife, Pernambuco, 2005.

GONÇALVES, W. Florestas urbanas. Viçosa: Revista Ação Ambiental. v. 9, n.1, p.17-19, 1999.

GONÇALVES, W.; PAIVA, H. N. de. Silvicultura urbana: implantação e manejo. Viçosa: Aprenda Fácil Editora, 2006. 
GREY, G. W. \& DENEKE, F. J. Urban forestry. New York: John Wiley, 1978.

IBGE - INSTITUTO BRASILEIRO DE GEOGRAFIA E ESTATÍSTICAS - Disponível em: <http://www.ibge.gov.br< Acesso em: 18 de Maio de 2010.

INSTITUTO DE TERRAS, CARTOGRAFIA E GEOCIÊNCIAS. Produtos de cartografia e geodêsia. Mapas. 2011. Curitiba. Disponível em:

<http://www.itcg.pr.gov.br/modules/conteudo/conteudo.php?conteudo=47>. Acesso em: 18 Fev. 2011.

LIMA, A. M. L. P. Árvores de rua. Revista Globo Ciência. São Paulo, n. 44. Março de 1995.

MAACK, R. Geografia Física do Paraná. 2.ed. Curitiba: Secretaria da Cultura e do Esporte do Governo do estado do Paraná, 1981.

MILANO, M. S. Planejamento da arborização urbana: relações entre áreas verdes e ruas arborizadas. In: Encontro Brasileiro Sobre Arborização Urbana. Anais... Curitiba: Sociedade Brasileira de Arborização Urbana, 1990. p.244-251.

MILANO, M. S.; DALCIN, E. Arborização de vias públicas. Rio de Janeiro: Light, 2000.

PARANÁ. Resolução SEAB nº 037, de 12 de abril de 2006. Dispõem sobre a proibição da murta (Murraya spp.) no estado do Paraná. In: Governo do Estado do Paraná, Curitiba, 2006. Disponível em:

<http://www.seab.pr.gov.br/arquivos/File/defis/citricultura/resolucao_037_murta.pdf. Acesso em: 8 jun. 2011.

RECCO, R. À sombra dos ipês da minha terra. Londrina: Midiograf, 2005.

RIBEIRO, F. A Arborização urbana em Uberlândia: percepção da população. Revista da Católica, Uberlândia, v. 1, n. 1, p. 224-237, 2009 - disponível em: < www.catolicaonline.com.br/revistadacatolica>. Acesso em 15 jan.2010.

RODRIGUES C. et al. Arborização urbana e produção de mudas de essências florestais nativas em Corumbá/MS. Corumbá: Embrapa Pantanal, 2002. Disponível em: <http://www.cpap.embrapa.br/publicacoes/online/DOC42.pdf>. Acesso em: 02/04/2010. 
SAMPAIO, A. C. Análise da arborização de vias públicas da área do plano piloto de Maringá/PR. Dissertação (Mestrado em Geografia) - Universidade Estadual de Maringá, Maringá, 2006.

SANTAMOUR JÚNIOR, F. S. Trees for urban planting: diversity uniformity, and common sense. In: Metria Conference, 7., 1990, Lisle. Proceedings... Lisle: 1990 p.57-66. Disponível em: <http://www.ces.ncsu.edu/fletcher/programs/nursery/metria/metria07/m79.pdfLisle.> Acesso em 16 jun. 2011.

SOUZA, V. C.; LORENZI, H. Botânica sistemática: guia ilustrado para identificação das famílias de Angiospermas da flora brasileira, baseado em APG II. Nova Odessa, SP: Instituto Plantarum, 2005 (2008 2 ed.).

VELASCO, G. N; LIMA, A. M. L. P; COUTO, H.T.Z. Análise comparativa dos custos de diferentes redes de distribuição de energia elétrica no contexto da arborização urbana. Sociedade de Investigações Florestais, Viçosa, v. 30, n. 4, p. 679-686. Disponível em: < http://www.scielo.br/pdf/rarv/v30n4/31690.pdf>. Acesso em 08 jun 2011. 